cedes properdin in the reaction sequence [1] (Fig. 1). Thus, the initiating factor could be the analogue of $\mathrm{Cl}$, and the nephritic factor may be the activated form.

A third pathway has been described which is initiated by antibody mediated activation of $\mathrm{Cl}$ and which utilizes components of the previously described alternative pathway. This proposed third pathway by-passes the use of $\mathrm{C} 4$ and $\mathrm{C} 2$ to activate C3-9 [26].

The attack of $\mathrm{C} 5$ by the $\mathrm{C} 5$ convertases derived from either the classical or alternative pathways initiates the self-assembly process which, without further enzymic action, results in the production of the stable C5b-9 complex (thought to be composed of equimolar amounts of $\mathrm{C} 5 \mathrm{~b}, \mathrm{C} 6$, $\mathrm{C} 7$, and $\mathrm{C} 8$ and six times as much $\mathrm{C} 9$ ) [1]. Theories proposing that the entire C 5 b-9 complex is either inserted into the membrane or that a small portion of the complex is extended through the membrane to allow exchange of intra- and extracellular constituents by means of internal hydrophilic channels have been put forward to explain the lysis of cells by complement $[1,3]$.

\section{References}

1 Muller-F.herhard H. I. (1975) Ann. Rev. Biochem. 44, 697-798

2 Lachman, P. J. (1973) in Defence and Recognition, Biochemistry Series One, pp 361-397, vol. 10 (Porter, R. R., ed.) Butterworths

3 Mayer, M. M. (1972) Proc. Nat. Acad. Sci. U.S.A. 69, 2934-2958

4 Pillemar, L., Lepow, 1.H., Ross, O.A., Todd, E.W. and Wardlaw, A.C. (1954) Science 120, 279-285
5 Spiegelberg, H. L. (1974) Advan. Immunol. 19 , $259 \ldots 294$

6 Kehoe, J.M., Bourgois, A., Capra, J.D., and Fougereau, M. (1974) Biochemistry 13, 2499-2504

7 Colomb, M. and Porter, R. R. (1975) Biochem. J. 145, 177-183

8 Il urst, M. M. . Volanakis, J. E., Stroud, R. M. and Bennet, J. C. (1975) J. Exp. Med. 142, 1322-1326

9 Low, T.L.K., Liu, Y.V. and Putnam, F.W. (1976) Science 191, 390. 392

10 Isenman, D. E., Dorrington, K. J. and Painter, R.H. (1975) J. Immunol. 114, 1726-1729

11 Lepow, I.H., Naff, G. B., Todd, E.W., Pensky, J. and Hinz, C. F. (1963) J. Exp. Med. 117, 938 1008

12 Gigli, I., Sim, R. B. and Porter, R. R. (1976) Biochem. $J$. (submitted for publication)

13 Metzger, H. (1974) Advan. Immunol. 18, 169-207

14 Schlessinger, J., Steinberg, I. Z., Givol, D., Hochman, J. and Pecht, I. (1975) Proc. Nat. Acad. Sci. U.S.A. 72, 2775-2779

15 Brown, J.C. and Koshland, M.E. (1975) Proc. Nat, Acad. Sci. U.S.A. 72, 5111-5115

16 Plaut, A.G., Cohen, S. and Tomasi, T. B. (1972) Science 176, 55-56

17 Reid, K. B. M. and Porter, R. R. (1976) Biochem. J. 55, 19-23

18 Knobel, H. R., Villiger, W. and Isliker, H. (1975) Eur. J. Immunol. 5, 78-82

19 Knobel, H. R., Heusser, C., Rodrick, M. L. and Isliker, H. (1974) J. Immunol. 112, 2094-2101

20 Kassel, B. and Kay, J. (1973) Science 180, 1022 1027

21 McClintock, D. K. and Bell, P.H. (1971) Biochem. Biophys. Res. Commun. 43, 694-702

22 Barkas, T., Scott, G.K. and Fothergill, J.E. (1975) Biochem. Soc. Trans. 1, 1219

23 Takahashi, K., Nagasawa, S. and Kogama, J. (1975) FEBS Lett. 55, 156-160

24 Gewurz, H. (1972) Biological Activities of Complement, p. 56 (Ingram, D. G., ed.), Karger, Base

25 Konno. T., Hirai, H. and Inai, S. (1975) Immunochemistry 12,773-777

26 May, J.E. and Frank, M. M. (1973) Proc. Nat. Acad. Sci. U.S.A. $70,649-652$

\title{
Ascorbic acid and drug detoxification
}

\author{
V.G. Zannoni and L.E. Rikans
}

Ascorbic acid plays a part in maintaining adequate drug detoxification and its biochemical mode of action is of current interest.

It has been shown by both in vivo and in vitro experiments that vitamin $\mathrm{C}$ deficiency in guinea pigs results in decreased metabolism of a variety of drugs, steroids and cholestcrol and that high supplements of the vitamin augment the activity of the drug enzyme system [1-5]. Our current knowledge of the liver microsomal pathway involved in the metabolism of many pharmacological agents is shown in Fig. 1. It involves an important heme protein,

Department of Pharmacology, the University of Michigan Medical School, Ann Arbor, Michigan 45109, U.S.A.

cytochrome P-450, which is reduced by NADPH via a flavoprotein, cytochrome P-450 reductase. For oxidative metabolic reactions the heme protein in its reduced state $\left(\mathrm{Fe}^{2+}\right)$ incorporates one atom of oxygen into the drug substrate and another into water. Many metabolic reductive reactions also utilize the hepatic cytochrome P-450 microsomal system. Associated with this important electron transport system is a lipid component, namely, phosphatidyl choline. Importantly, the hepatic drug metabolizing system is influenced by physiological and environ- mental factors which can affect the extent of detoxification [6]. For example, the activity of the microsonal system is markedly increased with chronic exposure to a great variety of agents such as barbiturates, carcinogens and environmental chemicals [7]. This induction is a type of drug-drug interaction in which a drug can cause an increase in its own metabolism as well as the metabolism of other drugs. It is obvious that ascorbic acid could participate at a variety of levels in this complicated hepatic microsomal system, and a number of laboratories have contributed to the elucidation of the biochemical basis for the vitamin's participation [3-5,8-14].

\section{Vitamin $\mathbf{C}$ deficient diet}

Adult guinea pigs maintained on a vitamin $\mathrm{C}$ deficient diet for 21 days had decreased overall drug metabolism, such as aniline hydroxylation, aminopyrine $N$ demethylation and $p$-nitroanisole $O$ demethylation, as well as decreased quantities of cytochrome P-450 and cytochrome $\mathrm{P}-450$ reductase. The liver microsomal ascorbic acid was about $40 \%$ of normal; the animals had lost, at most, $5 \%$ of their body weight and frankly were not scorbutic [11]. In addition, weanling guinea pigs (90-110 g and 1-2 weeks of age) placed on a vitamin $\mathrm{C}$ deficient diet for a relatively short period (8-15 days) also showed a decrease in drug metabolism activity and, when given high supplements of vitamin $C$, showed substantial increases in overall drug metabolism activity and quantity of electron transport components (Table I). Furthermore, fetal guinea pig livers showed a marked variation in cytochrome P-450 and $O$-demethylase activity which correlated well with the concentration of liver ascorbic acid [15]. Fetal livers with an ascorbic acid concentration of below $5.0 \mathrm{mg} / 100 \mathrm{~g}$ liver had no detectable cytochrome P-450 or $O$-demethylase activity while livers with high ascorbic acid levels (above $17.0 \mathrm{mg} / 100 \mathrm{~g}$ liver) had much higher drug metabolism activity; cytochrome P-450 concentration was $84 \%$ of the dams while $O$-demethylase activity was $51 \%$ of the control dams.

Specificity studies with other reducing agents used in place of ascorbic acid in vivo, such as reduced 2,6-dichlorophenolindophenol dye, reduced glutathione, and $D$-isoascorbic acid, indicated that the vitamin is relatively specific in that these reducing agents did not significantly affect the levels of cytochrome P-450, NADPH cytochrome $\mathrm{P}-450$ reductase or $p$-nitroanisole $O$-demethylation [15]. Reversals of decreased drug metabolism activities in vitamin $\mathrm{C}$ deficient animals by the in vivo administration of ascorbic acid showed that, although the quantity of liver ascor- 
bic acid was restored to normal levels within three days, most of the drug enzyme activities required 6-10 days of ascorbic acid administration to reach normal levels [11]. Other studies using phenobarbital indicated that protein synthesis is operable in vitamin $C$ deficiency in that overall drug oxidation activities (aniline hydroxylase, aminopyrine $N$-demethylase, and $p$ nitroanisole $O$-demethylase) and microsomal electron transport components were induced in vitamin $\mathrm{C}$ deficient guinea pigs comparable to the extent of induction in normal animals.

Kinetic studies with $O$-demethylase indicate no significant difference in the apparent affinity of $p$-nitroanisole in normal $\left(K_{m}=5.40 \times 10^{-4} \mathrm{M}\right)$, ascorbic acid deficient $\left(K_{m}=4.43 \times 10^{-4} \mathrm{M}\right)$ or animals given high supplements of the vitamin $\left(K_{m}=4.35 \times 10^{-4} \mathrm{M}\right)$. In addition, no significant differences were found in $K_{m}$
Glycine + succinyl CoA synthetase

$\delta$-aminolevulinic acid_dehydratase porphobilinogen $\rightarrow \rightarrow$ protoporphorin IX $\stackrel{\text { ferrochelatase }}{\longrightarrow}$ heme + apoprotein $\rightarrow$ cytochrome P-450.

Experiments were carried out to determine if vitamin $C$ deficiency affected the activity of $\delta$-aminolevulinic acid synthetase, the rate-limiting enzyme in heme synthesis as well as $\delta$-aminolevulinic acid dehydratase, the enzyme involved in the condensation of $\delta$-aminolevulinic acid to porphobilinogen [18]. Synthetase activity in liver homogenates from weanling guinea pigs placed on a vitamin $\mathrm{C}$ deficient diet for 14-18 days did not differ significantly from the activity from control guinea pigs given daily supplements of vitamin $\mathrm{C}$ in their drinking water $(1 \mathrm{mg} / \mathrm{ml})$. In addition, there were no significant differences in the $\delta$-aminolevulinic acid dehydratase activities.

TABLE I

The effect of in vivo administration of ascorbic acid on drug metabolism in weanling guinea pigs.

\begin{tabular}{|c|c|c|c|c|c|}
\hline Treatment & Ascorbic acid & P-450 & $\begin{array}{l}P .450 \\
\text { reductase }\end{array}$ & $\begin{array}{l}p \text {-Nitroanisole } \\
O \text {-demethylase }\end{array}$ & $\begin{array}{l}\text { Aminopyrine } \\
N \text {-demethylase }\end{array}$ \\
\hline Chow (5) & 27 & $0.068 \pm 0.002$ & $10.2 \pm 0.7$ & $10.5 \pm 1.0$ & $15.7 \pm 0.4$ \\
\hline $\begin{array}{l}\text { Ascorbate } \\
(25 \mathrm{mg})(6)\end{array}$ & 8 & $0.060 \pm 0.004$ & $7.5 \pm 0.8$ & $8.0 \pm 0.5$ & $15.9 \pm 2.3$ \\
\hline $\begin{array}{l}\text { Ascorbate } \\
(7 \mathrm{mg})(5)\end{array}$ & 6 & $0.060 \pm 0.004$ & $7.0 \pm 0.8$ & $7.5 \pm 0.5$ & $14.1 \pm 0.9$ \\
\hline $\begin{array}{l}\text { Deficient diet } \\
\text { (15-day) (6) }\end{array}$ & $<1.0$ & $0.047 \pm 0.002$ & $3.4 \pm 0.4$ & $2.6 \pm 0.2$ & $10.0 \pm 0.8$ \\
\hline
\end{tabular}

Weanling male albino guinea pigs, Hartley strain, were placed on various diet regimens as given in the table. Initial body weight of the animals ranged from 110 to $120 \mathrm{~g}$. The body weights of animals on the ascorbic acid deficient diet did not differ significantly from the other groups. Groups of animals given the deficient diet were supplemented with either 25 or $7 \mathrm{mg}$ of ascorbic acid given orally each day for 15 days. The number in parentheses equals number of animals in each group.

The concentration of ascorbic acid is given as $\mathrm{mg} / 100 \mathrm{~g}$ liver; cytochrome P-450 equals $\mu$ moles/ $100 \mathrm{mg}$ microsomal protein; cytochrome P-450 reductase activity equals $\mu$ moles $\mathrm{P}-450$ reduced per hr per $100 \mathrm{mg}$ microsomal protein at $27^{\circ} ; O$-demethylase activity equals $p$-nitrophenol formed per hr per $100 \mathrm{mg}$ microsomal protein at $27^{\circ} ; \mathrm{N}$-demethylase activity equals $\mu$ moles formaldehyde formed per hr per $100 \mathrm{mg}$ microsomal protein at 27 . Values are given as the mean \pm S.E.
It would be of interest to determine if there are any differences in ferrochelatase activity, since iron must be maintained in its ferrous state for incorporation into protoporphorin IX, and ascorbic acid could be involved at this level [19]. Furthermore, it will be of importance to examine degradation of cytochrome P-450, since a reduction of P-450 levels in ascorbic acid deficiency could also be due to an increased breakdown of the cytochrome.

\section{Physical differences in microsomes}

In contrast to the above results some differences in physical chemistry have been observed in microsomes prepared from deficient and normal animals. For example, cytochrome P-450 prepared from ascorbic acid deficient livers is less stable to sonication, dialysis, and treatment with metal chelators. The decrease in cytochrome $\mathrm{P}-450$ and $O$-demethylase activity associated with dialysis could be prevented by the addition of ascorbic acid $[14,16]$. Results from several different kinds of studies indicate that ascorbic acid may be closely associated with cytochrome P-450. The molar ratio of microsomal ascorbic acid to cytochrome P-450 was found to be in the order of $1: 1$, and this ratio was maintained during ascorbic acid deficiency in liver and adrenal tissue, during dialysis, on storage, and during partial purification of the cytochrome. In addition, ascorbic acid protects cytochrome P-450 and aniline hydroxylase activity from inhibition by ferrous iron chelators such as $\alpha, \alpha^{\prime}$ dipyridyl. The chelator reacts with cytochrome P-450 and prevents the formation of the reduced cytochrome $\mathrm{P}-450-\mathrm{CO}$ spectrum. $\alpha, \alpha^{\prime}$-Dipyridyl, in turn, gives a spectrum with the cytochrome at $450 \mathrm{~nm}$, and ascorbic acid protects the cytochrome constants with aminopyrine $\mathrm{N}$-demethylase in these groups [4]. Furthermore, the decrease in drug metabolism caused by ascorbic acid deficiency was not due to increased lipid peroxidation nor was there a significant qualitative or quantitative alteration in the important microsomal phospholipid component, phosphatidyl choline [14].

\section{Impairment of heme synthesis}

The possibility that the decreased quantity of cytochrome P-450 in ascorbic acid deficient microsomes may result from an impairment in heme synthesis was investigated. It was found that cytochrome P450 levels returned to normal when scorbutic guinea pigs were injected with $\delta$ aminolevulinic acid, a key substrate for heme biosynthesis [17]. A general scheme for the synthesis of heme is indicated below.

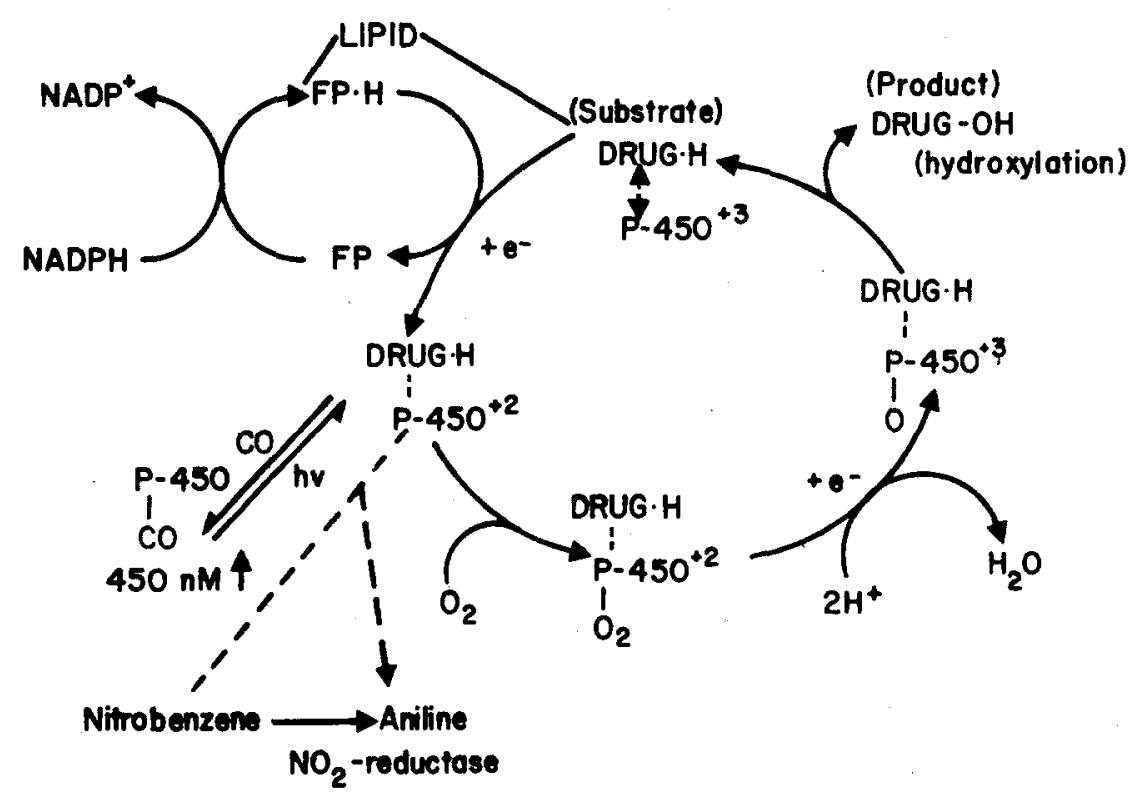

Fig. 1. Hepatic microsomal electron transport for drug oxidation and reduction. 
from interaction with the chelator. The formation of a $\mathrm{CO}$ ligand with reduced cytochrome $\mathrm{P}-450$ is the basis of determining the quantity of heme protein in the microsomes (Fig. 1). These studies suggest that there is an interaction between ascorbic acid and cytochrome P-450, involving the reduced form of the heme iron $[14,16]$.

The need for vitamin $C$ in the detoxification of drugs in humans may be important, especially during growth. In addition, the possibility should be considered that those individuals with insufficient intake of vitamin C may show sensitivity and possible toxicity to drugs. This would be true, for example, if increased formation of metabolites is necessary to ensure adequate detoxification. Of interest would be the time required for humans on a low intake of vitamin $\mathrm{C}$ to re-establish sufficient levels of drug metabolism after supplementation with the vitamin. In this respect increasing the intake of ascorbic acid in man above the recommended allowance $(70-75 \mathrm{mg}$ per day) to observe the effect on the biological plasma half-life of a variety of drugs as well as steroids and cholesterol may be of clinical importance.

\section{References}

1 Conney, A. H., Bray, G. A., Evans, C. and Burns, J. J. (1961) Ann. New York Acad. Sci.92, 115-127

2 Conney, A.H. and Burns, J.J. (1962) Advan Pharmacol. 1, 31-58

3 Zannoni, V.G. and Lynch, M.M. (1973) Drug Metab. Rev. 2, 57-69

4 Zannoni, V.G., Lynch, M. M. and Sato, P. H (1974) in Perinatal Pharmacology: Problems and Priorities (Dancis, J. and Hwang, J. C., eds), pp. 131-147, Raven Press, New York

5 Ginter, E. (1973) Science 179, 702-704

6 Conney, A.H. (1967) Pharmacol. Rev. 19, 317-366

7 Conney, A. H. (1971) in Fundamentals of Drug Metabolism and Drug Disposition (La Du, B. N., Mandel, H.G. and Way, E. L., eds), Chap. 13, pp. 253-278, Williams \& Wilkins Co., Baltimore

8 Richards, R. K., Keuter, K. and Klatt, T. I. (1941) Proc. Soc. Exp. Biol. Med. 48, 403-409

9 Axelrod, J., Udenfriend, S. and Brodie, B. B. (1954) J. Pharmacol. Exp. Ther. 11 1, 176-181

10 Kato, R., Takanaka, A. and Oshima, T. (1969) Jap. J. Pharmacol. 19, 25-33

11 Zannoni, V. G., Flynn, E. J. and Lynch, M. (1972) Biochem. Pharmacol. 21, 1377-1392

12 Degkwitz, E. and Kim, K.S. (1973) HoppeSeyler's Z. Physiol. Chem. 354, 555-561

13 Sato, P. H. and Zannoni, V. G. (1974) Biochem. Pharmacol, 23, 3121-3128.

14 Sato, P. H. and Zannoni. V. G. (1976) J. Pharmacol. Exp. Therap. (in the press)

15 Zannoni, V.G. and Sato, P. H. (1975) Ann. New York Acad. Sci. 258, 119-131

16 Sato, P. H. (1975) Ph.D. Thesis, New York University, New York

17 Degkwitz, E., Walsch, S., Dubberstein, M. and Winter, J. (1975) Am. New York Acad. Sci. 258, 201-208

18 Kappas, A., I evere, R. D. and Granick, S. (1968) Seminars in Hematol. 5, 323-334

19 Burnham, B. F. (1968) Seminars Hematol. 5 296-322

\title{
Brown fat mitochondria
}

\author{
David G. Nicholls
}

\section{Brown fat mitochondria can short-circuit their respiratory chain to generate heat.}

Our normal response to cold is to shiver. Shivering is caused by small muscular contractions which dissipate metabolic energy as heat and so help to restore our body temperature. There is, however, an alternative mens of generating heat under certain conditions which has been termed 'non-shivering thermogenesis', and which is important at birth, when an immense cold-shock must be overcome very rapidly, as well as being vital for the cold-adaptation of a variety of small mammals. Nonshivering thermogenesis is, in addition, an essential mechanism for hibernators, as heat can be generated even when the animal's body temperature is very low, and thus prevent the animal from literally freezing.

The most important site of non-shivering thermogenesis is in brown fat, a tissue which appears to be specialized solely for heat production. The tissue is perfectly adapted to its role. It can increase five-fold in weight on cold-adaptation, and has an ingenious blood supply which is directed towards warming the vital organs and which also involves a system of countercurrent heating to ensure that blood entering the tissue is as warm as possible [1,2]. The cells contain many triglyceride droplets, and most of the remaining cytoplasm is packed with highly active mitochondria [2]. The tissue is controlled by the sympathetic nervous system which has noradrenalin-containing synapses in contact with the cells [2]. Release of the transmitter activates cyclic AMP production, which in turn activates a lipase, releasing free fatty acids as substrate for the mitochondria. The way in which brown fat mitochondria are adapted to handle this terminal oxidation is the subject of this article.

\section{Physiological 'uncoupling'?}

Mitochondria normally function to minimize the dissipation of chemical energy as heat, and one way that this is achieved is by a tight coupling of respiration to ATP production. For example, the high respiratory rate of exercising muscle is a consequence of the mitochondria

Department of Psychiatry, University of Dundee, Ninewells Medical School, Dundee, Scotland, U.K. attempting to restore the cytoplasmic ATP levels which were lowered by the ATPase action of the muscle. In brown fat, however, no such potent ATP-hydrolysing system can be found to account for the very high rates of respiration of which the tissue is capable [2-4]. If no way exists of hydrolysing ATP at a sufficient rate, then it follows that little ATP can be synthesized in the first place; in other words that brown fat mitochondria can uncouple the oxidation of fatty acids from the production of ATP. The isolated mitochondria have therefore been studied intensively in an attempt to localize the molecular nature of this 'uncoupling' (for reviews, see [2-4]).

\section{The proton circuit}

The chemiosmotic theory of Mitchell $[5,6]$ provides a framework within which to investigate such physiological uncoupling. The proton circuit, the essence of the theory, is shown on p. 129. Substrate oxidation by the respiratory chain is linked to the expulsion of protons from the mitochondrial matrix, leading to the build-up of a proton electrochemical gradient (or protonmotive force) across the membrane which is analogous to the voltage developed by a battery, and is usually expressed in millivolts. Just as an electrical circuit requires a continuous pathway of electron conductors for current to flow, in the same way the proton circuit must be completed by some pathway that conducts protons back through the inner membrane. In most mitochondria the predominant pathway of proton re-entry is via the ATPase, the drop in potential of the protons being used to drive the energetically unfavourable synthesis of ATP.

Mitchell proposed [5,6] that not only was respiration tightly linked to the expulsion of protons, but also that proton reentry was tightly linked to the production of ATP, so that when the cell had no further need for ATP synthesis, the proton current through the ATPase stopped, with the result that the proton electrochemical gradient built up, stopping further proton release (and hence respiration) by the respiratory chain. Clearly this automatic respiratory control could be overcome in two ways: if the link between respiration and proton extrusion could be broken, or if a way could be found of allowing pro- 